\title{
An InNovative APPROACH OF Metrology FOR High PRECISION AND QUALITY MACHINING TOOL ASSESSMENT IN THE INTEGRATED Production EngineERing
}

\author{
Gokcen Bas $^{\mathrm{a}}$, Numan M. Durakbasa ${ }^{\mathrm{a}}$, Ildiko Mankova ${ }^{\mathrm{b}}$, Marek Vrabel ${ }^{\mathrm{b}}$ \\ ${ }^{a}$ Vienna University of Technology, Getreidemarkt 9 BA-09, Vienna 1060, Austria \\ ${ }^{b}$ Technical University of Košice, Faculty of Mechanical Engineering, Letná 9, 04001 Košice, Slovakia
}

\begin{abstract}
Production metrology provides essential information for the operational and industrial environment with regards to the completion of products, working conditions and status of the processes. Researchers have been working on both laborious experimental work and numerical modeling to overcome the challenges of the modern manufacturing industry that requires high quality and precision. Therefore, this study focuses on investigation of the analysis of the high precision measurement results targeted towards improvement of the quality of the end product as well as the appearance and surface finish for geometric and work accuracy. The aim of the study is integrating advanced metrology methods into the machining industry that will enable the industry to operate competitively introducing higher quality end products as well as efficiency and savings.
\end{abstract}

Keyword:Production; precision metrology; process quality; surface metrology; geometrical product specification (GPS)
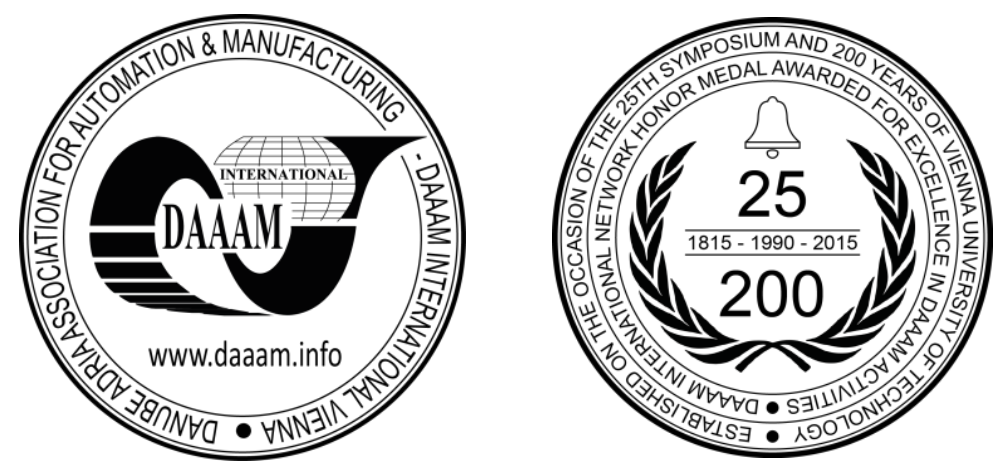

This Publication has to be referred as: Bas, G[okcen]; Durakbasa, N[uman] M[.]; Mankova, I[ldiko] \& Vrabel, $\mathrm{M}$ [arek] (2016). An innovative approach of metrology for high precision and quality machining tool assessment in the integrated production engineering, Proceedings of the 26th DAAAM International Symposium, pp.0787-0794, B. Katalinic (Ed.), Published by DAAAM International, ISBN 978-3-902734-07-5, ISSN 1726-9679, Vienna, Austria DOI:10.2507/26th.daaam.proceedings.110 


\section{Introductory Remarks}

Production metrology plays an important role in needs of modern manufacturing companies to improve the quality of the final product as well as their functional needs of application. The processes of instrumentally measurement of the parameters during realization of the desired products may be challenging and costly. Hence, functional testing taking into account the materials, their geometrical properties as well as topographies will enable savings of a considerable expense together with introducing the means of an efficient metrological assessment. According to the functional specifications of a workpiece, which are derived from the functional need, the geometrical specifications will be set up during the design stage. In this first step to the product realization in a manufacturing plant, the field of permissible deviations of a set of characteristics of a part will be defined. It shall determine a high level of quality in conformance with manufacturing processes, the limits permissible for manufacturing, and the definition of the conformity of the workpiece [1].

The machining during the manufacturing process is the essential factor that defines the conformity of the end product. The development of new machining tools has been indispensable due to the modern machining industry requirements in both production process and materials. The present trends show that the manufacturing methods and materials demand the need of highest possible productivity level. During the last decades, there have been studies investigating the effects of the machining tool parameters, which aim longer life-time of the tools and higher performance $[2,3,4]$. The studies continue further investigations on the material compositions and geometries, as the surface finish and functionality improves by introduction of new applications $[5,6,7]$. The selection of the cutting parameters is found to be essential for fulfilling the high quality of the products $[8,9]$.

This study represents the assessment of the structure and form of the cutting edge of the tools by means of both tactile and optical measurements under the guidance of international standards. Surface characteristics and roughness of the machining tools are obtained to create a database of cutting tool information to provide further correlation in the tool development. Moreover, in this study, integration of the micro- and nano-precise metrological methodology carried out in a high precision measurement laboratory into the industrial requirement has enabled a strategy for the industrial requirement of improved, high quality machining. The target is integrating advanced metrology methods into the machining industry that will enable the industry to operate competitively introducing efficiency and savings.

\section{Key enable metrology applications for the machining industry}

Correlation between the machining tool wear on the cutting edge regions and surface roughness variation is an important feature to evaluate the state of the tool edge in developing machining process that is possible through micro/nanometrology. Moreover, the material structure change observed in machining process presents the technological data required for development [10].

The experimental tool life determination for real applications of the machine industry is more complex than its suggested mathematical models. The ISO Standard 8688 guides us on the deterioration of tools due to the tool wear [11]. However the machining tool deterioration must be investigated as a total effect of wear, edge fracture and deformation. Therefore the machining cutting tool lifetimes are assessed based on the cutting time and process variables using the response surfaces. The mathematical model of a tool lifetime under constant depth of cut (mm) and feed rate (mm/tooth) using the Taylor's model is as in the Equation.1 [12]:

$$
T n=\frac{C}{V}
$$

where

$$
\begin{array}{ll}
\mathrm{T} & \text { : predicted tool lifetime }(\mathrm{min}) \\
\mathrm{V} & \text { : cutting speed }(\mathrm{m} / \mathrm{min}) \\
\mathrm{C}, \mathrm{n} & \text { : constants (process and material) }
\end{array}
$$

determination of constants in the mathematical model, a logarithmic transformation must be performed. The quality of machining with the machining tools is affected with the process constants and surface parameters. Due to the importance of the process parameters and the surface characterisation, a methodology is introduced to be integrated into a machining industrial company. The aim is to accomplish the following key mechanisms under guidance of quality management [13]:

- Process Quality Control

- Product Quality Control

- Machine and Tool Monitoring

- Organizational Management Control

- $\quad$ Testing 
- Efficiency

- Cost Analyze

- Standards \& Guidelines Compliance

- Continuous Improvement

With the advent of a management system, the integral aspects of more sophisticated management strategies would be applied competently within the standards in the same organization [14]. It is based on Plan-Do-Check-Act cycle (Deming Cycle) that can be integrated into any kind or size of an organization that has a proven success record with continuous process steps in management systems (Fig.1).

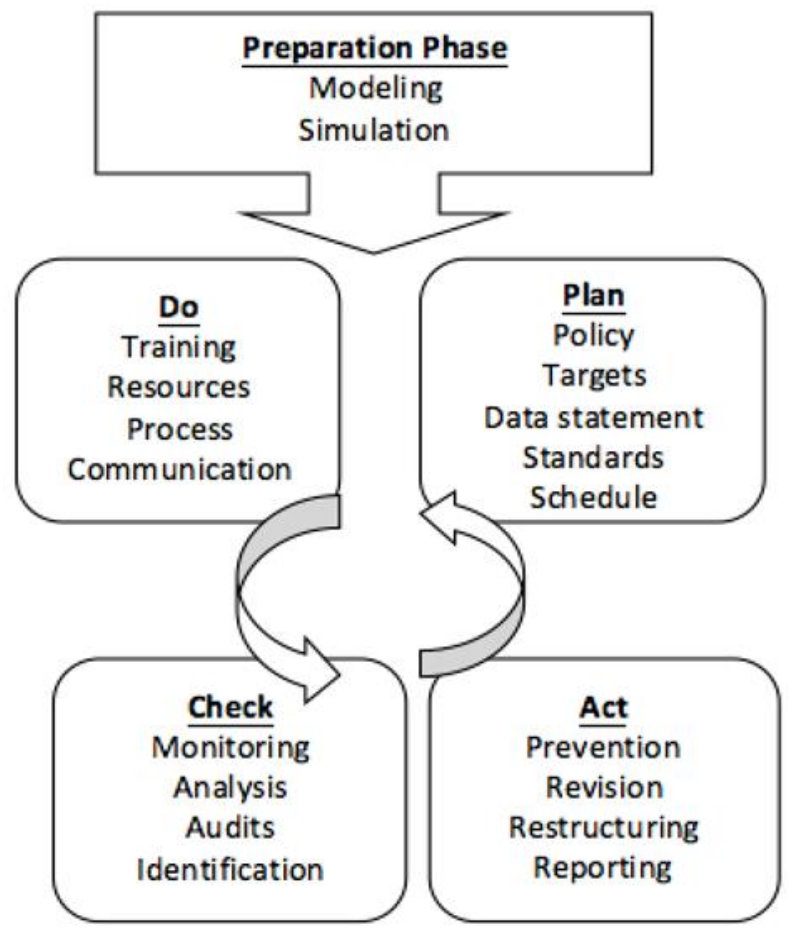

Fig. 1. Methodology Integration of the Quality Management Process

High product quality can only be achieved if the metrology is integrated tightly to the production process as close as possible. Because of the quality, the assurance and metrology form an inseparable unit in the process of manufacture. The European and international standardization on quality management systems form the fundamentals and general trend to higher expectations on the quality of end products.

\section{Surface and structure characterisation}

If the workpiece geometry of machined parts is considered as a whole there exist interactions between the different features forming the periphery of the part. But also within the surface of every single feature there exist interactions between geometrical deviations of different kind and different order. The definitions of surface and structure characterisation that will fit into the machining tool assessment can be represented as in the Table 1.

\begin{tabular}{ll}
\hline Term & Definition \\
\hline Surface Character & $\begin{array}{l}\text { This refers to the errors that are introduced as a result of the } \\
\text { feed effects of the machining tool. Sometimes this is a } \\
\text { vibration of the tool producing a cyclic effect. }\end{array}$ \\
This refers to the roughness that is caused as a result of the \\
manufacturing action whilst generating the surface and \\
includes the micro shearing between the surface and the \\
machining tool. \\
This refers to the errors that are introduced as a result of the \\
inaccuracies in slideways and also thermal imbalance within \\
the machine structure that can introduce additional long \\
wavelength errors within a surface.
\end{tabular}

Table 1. Surface and Structure Characterisation 
The surface and structure assessment can be used in the area of modern machining to develop some definitions that are necessary to achieve the characterisation [15]. During the machining process, there are the milli-meter effects that relate to the surface form as a result of the cutting and feeding action of the cutting tool itself. The micro-meter effects refer to cutting action and occur at the tool chip interface. Finally, the nano-meter effects are observed that can provide useful information on the effects of the atomic lattice of the material of the finally machined surface where we require measuring instruments devised to cater for the surfaces and structures down to the $0.1 \mathrm{~nm}$ level (Table 2).

\begin{tabular}{ll}
\hline Limit size & Measuring techniques \\
\hline $10 \mathrm{~nm}-1 \mathrm{~nm}$ & $\begin{array}{l}\text { Laser confocal microscope, X-ray microanalyzer, SEM, SPM } \\
\text { (STM, AFM), electron and X-ray diffraction system }\end{array}$ \\
$100 \mathrm{~nm}-10 \mathrm{~nm}$ & $\begin{array}{l}\text { CMM, Laser interferometers, roughness measuring devices, } \\
\text { fluorescence microscope }\end{array}$ \\
$1 \mu \mathrm{m}-100 \mathrm{~nm}$ & $\begin{array}{l}\text { CMM, Computer topography, Electromagnetic and } \\
\text { electrostatic comparator, optical interferometer, phase } \\
\text { microscopes, dark field microscopes }\end{array}$ \\
\hline
\end{tabular}

Table 2. Measurement techniques related to measuring capability

\subsection{High precision measurement room - nanometrology laboratory}

The characterisation of the micro- and nanogeometry of the cutting edge of the machining tools is often challenging due to the experimental precision measurements. A detailed analysis and adaptation of machine tools and the production environment is mandatory to ensure an efficient process and successfully enable desired machining [16]. In this study, the surface roughness characterisation process was carried out by micro-/nanometrology devices in order to overcome the challenges by predefined limits in compliant with the international standards.

The requirements of a micro-/nano-metrological assessment must cover three major scientific attributes:

- Reliability: Measurement results have to mirror the real surface structure and statistic and systematic errors may be reduced to an absolute minimum.

- Comparability: Measurement results must be comparable when they are measured with different measurement systems of the same kind. Ideally measurement results taken with different systems should be comparable too.

- Reproducibility: Several measurements of the same sample under the same conditions must result in the same results. Changes in measurement conditions must result in comprehensible changes in the measured parameters.

Having the expertise to carry out the major scientific metrological procedures as indicated above, required standards and norms are also used throughout this study. The measurements of this study was performed at Vienna University of Technology, Department of Interchangeable Manufacturing and Industrial Metrology, High Precision Measurement - Nanotechnology Laboratory where the environmental disturbances of temperature, humidity, vibration are kept constant and under control with air conditioning facility of a dust filter providing a clean room for accurate assessment.

\subsection{Micro-/nano-metrological assessment}

There has been a distinction between form errors of different order both in the technical literature and the relevant standards for the analysis of workpiece surfaces. It has been a common practice to collectively measure the surface roughness on the basis of worldwide understood and internationally established parameters. On that basis, the stylus instruments have been developed that are used very commonly especially in industrial practice [17].

In this study, tool quality of cutting edges of the selected high precise cylindrical cutting tools was investigated in micro and nano-scale (Fig.2).

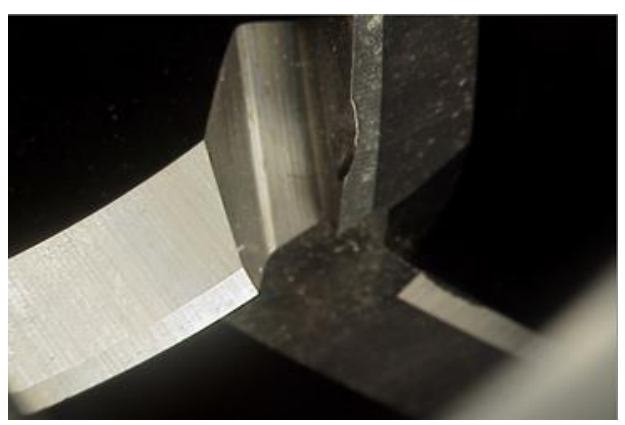

Fig. 2. The tool quality assessment using a digital microscope 
The analyses of the surfaces of the cutting tools were performed for physical vapor deposition (PVD) AlTiN coated machining tools (Fig.3) [18].

The measurement results presented (see Fig.4) are the surface roughness measurements in micro/nano scale by the profilometer of $60 \mathrm{~mm}$ stylus arm length, $2 \mu \mathrm{m}$ radius conisphere diamond stylus tip size and $1 \mathrm{mN}$ force (speed=1 $\mathrm{mm} / \mathrm{s}$ ) according to the ISO 4287 [19] The results indicate a slightly higher average roughness values on the coated tools, which is a critical finding effecting machining industry tool performance.
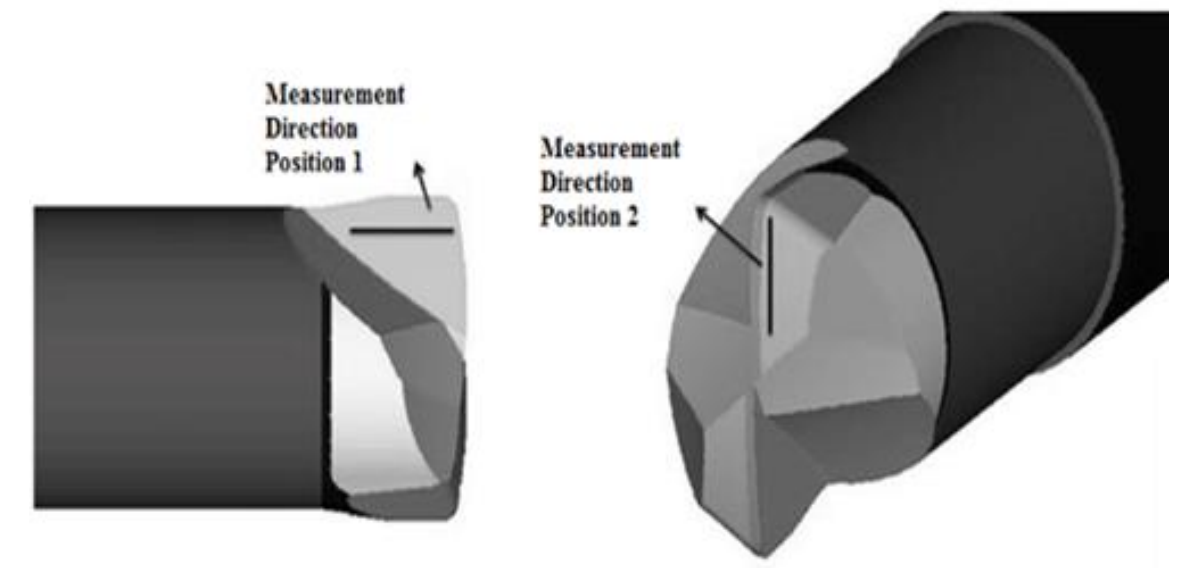

Fig. 3. The measurement surface area indication on the machining tools.

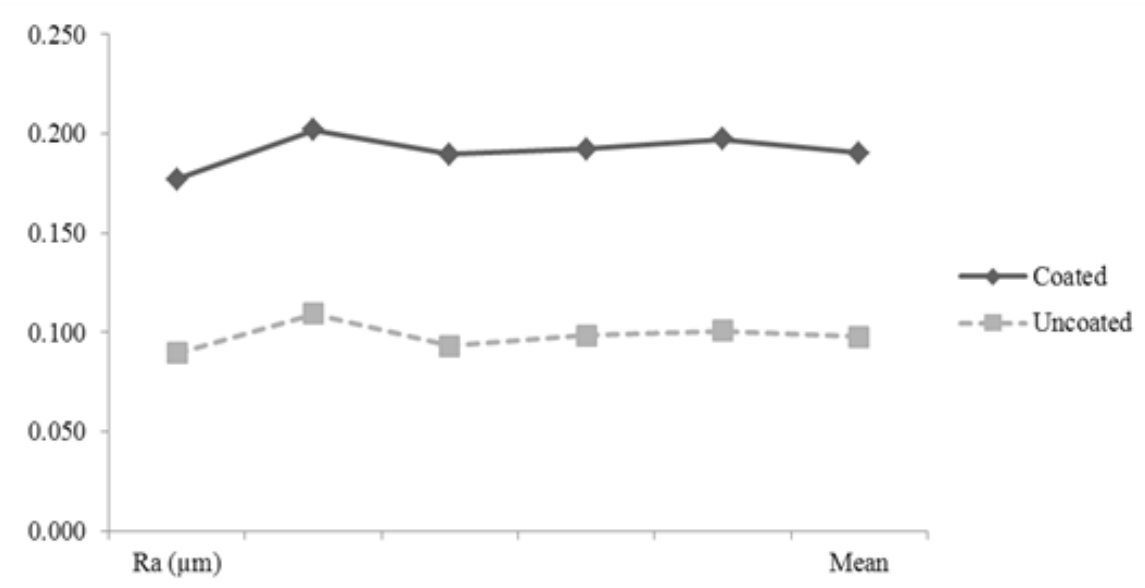

Fig. 4. Average surface roughness measurement results of the coated and uncoated machining tool flanks

The surface topography and structure assessment was performed further by the optical capturing of the magnified images by CCD camera of a laser scanning microscope as presented in the Fig.5, Fig.6 and Fig.7.

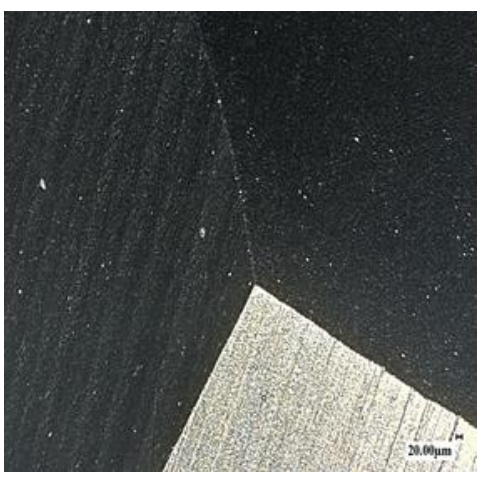

(a)

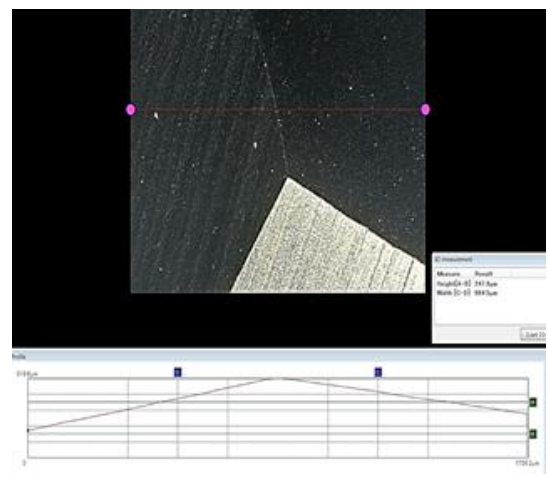

(b)

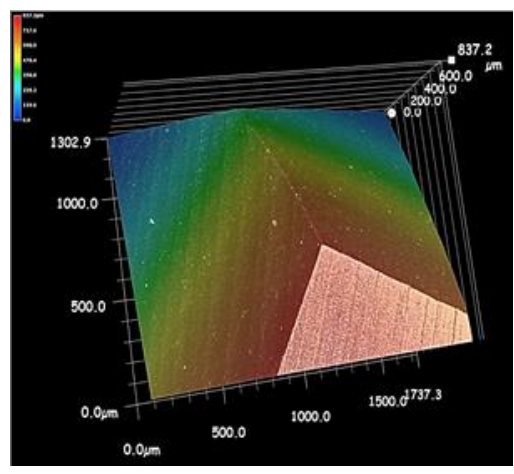

(c)

Fig. 5. (a) (b) (c) 2D\&3D surface topography and geometrical assessment of the coated machining tool flanks using a laser scanning microscope 


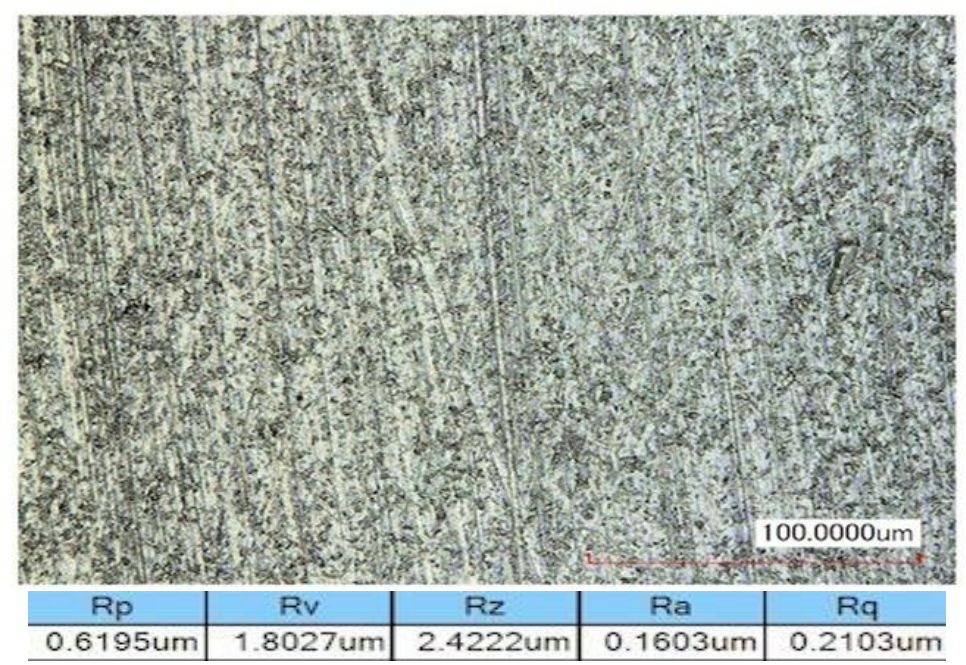

Fig. 6. The surface roughness values measurement of the machining tool flank using a laser scanning microscope.

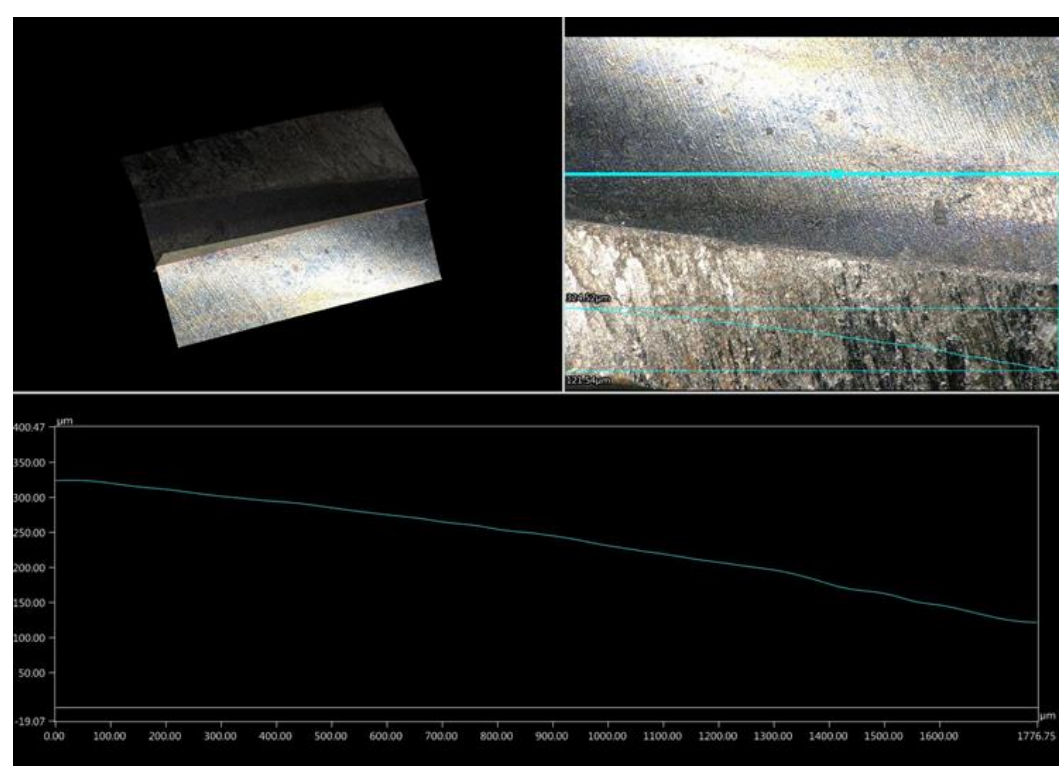

(a)

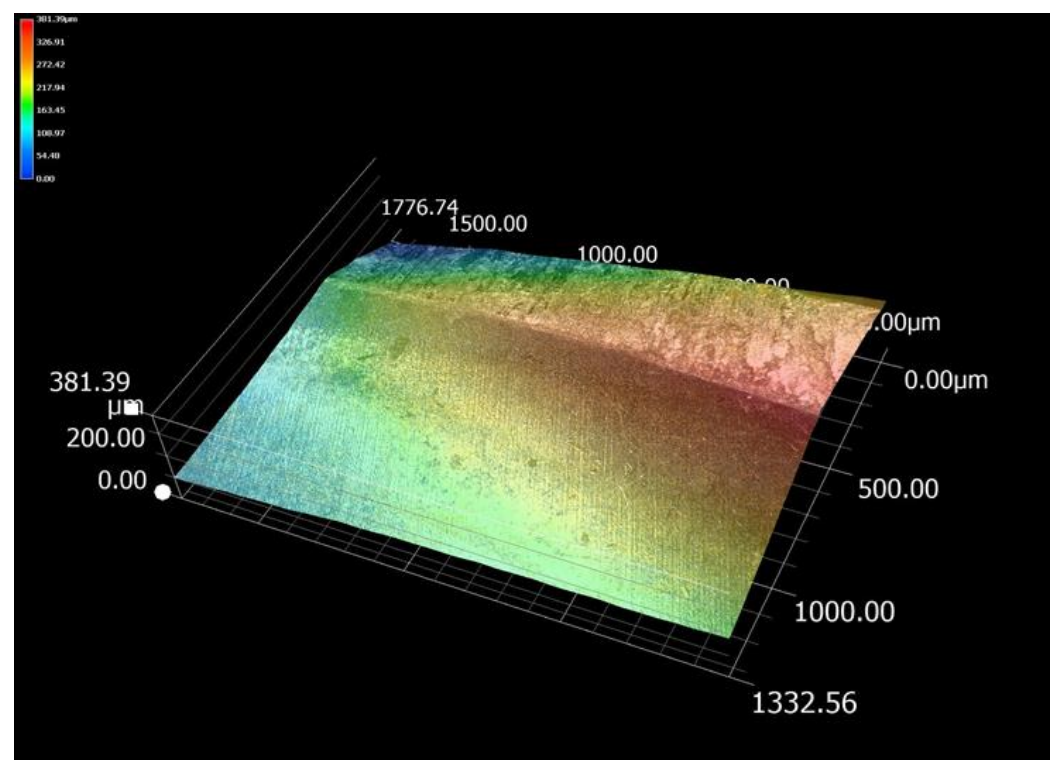

(b)

Fig. 7. (a) (b) 2D\&3D surface topography and geometrical assessment of the uncoated machining tool flanks using a laser scanning microscope. 


\section{Conclusion}

There exists close interaction between precision metrology and novel industrial and technological developments in the field of machining. The novel improvements of the metrology techniques have enabled to feature high-tech instruments that can acquire an accurate surface and structure characterisation of the machining tools and fulfil the requirements for the application in modern industrial environment.

Quality control and especially surface structure metrology and geometrical assessment are essential tasks when precision machining shall be carried out under economic conditions. This study proposes an approach of metrology for high precision and quality machining tool assessment in the integrated production engineering with developments in metrology and instrumentation. Moreover, the high precision measurements compliant with the international standards are carried out to examine the cutting edge of the machining toll samples in both 2D and 3D metrological investigations. The micro- and nano-scale measurements have been stored in order to creative both qualitative and quantitative data on edge cross-sections that is known to be the most influential region for quality and life-time of the machining tools. This methodology of precision measurement will produce necessary data for the modern manufacturing, which advances towards miniaturization with micro- and nano-particles and geometries in requirement of smaller tolerances.

There is a huge prospect of modern machining tool development and their micro- and nano-scale applications. Hence, this study also proposes a roadmap for the assessment of machining tools by means of the laboratory equipments, which are already available providing a research opportunity and cost-efficient further developments. This proposal of integration of the micro- and nano-metrological assessment with existing expertise will enable improvement in both research and industrial applications that is required by modern technology quality and precision machining.

\section{References}

[1] ISO 17450-1:2011, Geometrical product spesifications (GPS) - General concepts - Part 1: Model for geometrical specification and verification.

[2] M. Dosedla, Machine Tool Life-Cycle, Annals of DAAAM for 2009 \& Proceedings of the 20th International DAAAM Symposium, ISSN 1726-9679, Vienna, 2009, pp. 0075-0076.

[3] B. Karpuschewski, O. Byelyayev, V.S. Maiboroda, Magneto-abrasive machining for the mechanical preparation of high-speed steel twist drills, CIRP Annals - Manufacturing Technology vol. 58, 2009, pp. 295-298.C. Boieriu, I. Curtu, M.C. Timar, D. Lica, Quality of finished surfaces for Lignin-Cellulose based materials, Annals of DAAAM for $2008 \&$ Proceedings of the 19th International DAAAM Symposium, ISSN 1726-9679, Slovakia, 2008, pp. 0123-0124.

[4] M.N. Durakbasa, A. Akdogan, A.S. Vanli, A.G. Bulutsuz, Optimization of end milling parameters and determination of the effects of edge profile for high surface quality of AISI H13 steel by using precise and fast measurements, Measurement, 68, 2015, pp. 92-99.

[5] P.C. Priarine, S. Rizutti, L. Settineri, G. Vergnano, Effects of cutting edge angle, edge preparation, and nanostructured coating on milling performance of a gamma titanium aluminide, Journal of Materials Processing Technology vol. 212, 2012, pp. 2619-2628.

[6] A. Salihu, H.M. Zeqiri, A. Bunjaku, N.E. Qehaja, F. Zeqiri, Research of surface roughness average of steel C45 during turning, Annals of DAAAM for 2010 \& Proceedings of the 21st International DAAAM Symposium, ISSN 1726-9679, Croatia, 2010, pp. 0185-0186.

[7] H. Yanda, J.A. Ghani, M. Rizal, C.H. Che Haron, Performance of uncoated and coated carbide tools in turning fcd700 using Fem simulation. International Journal of Simulation Modelling (IJSIMM), 14(3), 2015.

[8] A. Weckenmann, K. Nalbantic, Precision measurement of cutting tools with two matched optical 3D-sensors, CIRP Annals-Manufacturing Technology 52.1, 2003, pp. 443-446.

[9] R. Dubovska, J. Majerik, I. Baska. Experimental measurement of Cutting Forces in the Turning technology, DAAAM International Scientific Book 11, 2012, pp. 255-266.

[10] I. Mankova, G. Markova, Evaluation of surface microgeometry when grinding and finish turning of hardened steel, in 3Rd ICPM 2005, ISBN3-901-888-31-4, Vienna, 2005, pp. 231-238.

[11] ISO 8688-2, Tool life testing in milling - Part2: End milling, 1989.

[12] N.P. Hung, F.Y.C. Boey, K.A. Khor, Y.S: Phua, H.F. Lee, Machinability of aluminum alloys reinforced with silicon carbide particulates, Journal of Materials Processing Technology 56 (1996), pp. 966-977.

[13] EN ISO 9001:2015, Quality management systems - requirements.

[14] M.N. Durakbasa, P.H. Osanna, Quality in Industry, Department for Interchangeable Manufacturing and. Industrial Metrology, Vienna University of Technology, Vienna, 2009.

[15] R. Leach, A. Weckenmann, J. Coupland, W. Hartmann, Interpreting the probe-surface interaction of surface measuring instruments, or what is a surface?, Surface Topography: Metrology and Properties, 2(3), $2014,035001$.

[16] G. Varga, J. Kundrak, Effect of environmentally conscious machining on machined surface quality, Applied Mechanics and Materials 309, 2013, pp. 35-42. 
[17] M.N. Durakbasa, P.H. Osanna, Intelligent Tolerancing And Advanced Metrology To Support Total Quality Management And Modern Industrial Fabrication, International Journal "Total Quality Management \& Excellence", 1, Vol.39 (2011), UDK 658.5; pp. 27-31.

[18] M.N. Durakbasa, A. Akdogan, S. Vanli, A. Günay, Surface Roughness Modeling with Edge Radius and End Milling Parameters on Al 7075 Alloy Using Taguchi and Regression Methods, Acta Imeko, Volume 3, 2014, 4; pp. 46-51.

[19] DIN EN ISO 4287:2010-07, Geometrical Product Specifications (GPS) - Surface texture: Profile method - Terms, definitions and surface texture parameters (ISO 4287:1997 + Cor 1: 1998 + Cor 2: 2005 + Amd 1: 2009). 